\title{
Somatic education and embodied discourses: Using the Feldenkrais Method to challenge dominant discourses in the sexually abused body context
}

Lucie Beaudry, Université du Québec à Montréal

\begin{abstract}
In an autoethnographical study for a master's degree in dance, the author shares how somatic education enabled her to challenge the dominant discourses that were integrated following the incest she experienced in her childhood. Considering that our identities are a function of the constraints that act on us and influence our subjectivity, the author explains how these discourses have influenced her relationship to her body and how the Feldenkrais Method made a new perception of self and of the world possible. She describes her experience of the self-educating process, a process that revealed the plasticity of a self capable of adapting to the whole of her life experiences. From the development of somatic authority to creative self-fashioning, the author draws from a variety of inspirations to nurture her thinking about, and show the role played by, somatic education.
\end{abstract}

\section{Keywords}

dominant discourses, somatic education, Feldenkrais Method, self-consciousness, subjectivity, body-as-object, self-education 


\section{Introduction}

This article is based on an autoethnographical study (2011) that made it possible to understand my difficult 30-year relationship to myself following my experience of incest, a relationship deeply rooted in the objectivization of my body. Over a three and a half year period, the study documented - by way of a journal, creative writing and visual arts - how somatic education empowered a gradual reconnection with a body-as-subject, a process that greatly contributed to the development of my subjectivity and reflexivity. I arrived at an understanding of the full impact that the incest and the subsequent family discourses had on my perception of myself and my relationship to myself, an experiential knowing made possible by the practice of somatic education. The research has thus demonstrated that somatic education can foster a connection to self and a self-realization leading to greater freedom of being, doing and thinking. The aim of this article is to demonstrate how such an impact was made possible.

This article presents the family context and discourses to which I was exposed along with a summary of their consequences on my relationship to myself that was to develop. Because the integration of these discourses shaped the way I experienced my body, the study focused especially on the objectivization of my body that resulted. This body-as-object relationship led me to the discovery of somatic education and to the process of self-education elaborated by the Feldenkrais Method in particular. In the article, I document how I reconnected with my subjectivity through my somatic studies. Inspired by this process, I reflect on corporeity, the development of somatic authority, creative self-fashioning and selfing advocated by the Feldenkrais Method. The results of the study demonstrate the potential that somatic education offers for emancipating and reharmonizing the self. 


\section{Impact of family discourses on the construction of the self}

According to philosopher Michel Foucault (1975), subjectivity corresponds to identity and identity is the product of ideologies and discourses. We construct ourselves, but we do so according to the constraints acting on us and that influence our subjectivity. In this sense, subjectivity is not a structure imposed on us, but neither can we construct ourselves entirely as we wish. Our subjectivity encompasses history and context, it develops within a given social order. While our actions truly do belong to us, they nevertheless unfold within norms and practices that we have not necessarily chosen. These standards are in a certain way the rules of the game we have to deal with.

I was a victim of incest between the ages of 4 and 5 and my abuser was my uncle, who came from a family of ten children, and who regularly babysat my younger brother and me. At first I liked him. Supposedly because I was the eldest, he often let me have little privileges such as going to bed a little later than my brother. These favours gradually went in another direction, and I was well manipulated as the game progressed. Once caught in the trap, I was reduced to silence by a variety of intimidation strategies. It took me about a year to denounce my abuser. Fortunately, when my parents found out, they believed me.

When the abuse ended, my parents dealt with it in such a way as to avoid making waves (staying silent). Making the whole thing disappear seemed to be the preferred option. We lived in a small town where everyone knew everyone else and where gossip travelled fast. Silence seemed to offer the family the only protection from getting mucked on. Under this crisis management 
approach where it didn't occur to anybody to seek out psychological support, I was exposed to the family discourses that occasionally borrowed from Judaeo-Christianity and would influence the construction of my identity and the way I lived my body.

First, my family was in denial: it's best to forget about all of that. According to the people closest to me, it would be better for everyone involved to turn a blind eye and move on. Talking about it wasn't going to change anything. I was asked to ignore these events, arguing that after all, we should try to forgive. Raised within a religious and practicing family, I was basically told that forgiveness was obligatory and that one must always avoid hurting other people's feelings. Within this Judaeo-Christian discourse, where the other is more important than oneself, selfsacrifice was a must. I wasn't allowed to pay attention to what I had experienced, let alone prioritize how I felt. Then came the normalization, even the trivialization of the events: it has happened to many other girls besides you. I was told that indeed, my case wasn't exceptional and that even worse things had befallen others. Therefore, I was expected to be resilient: you have to learn to live with it. Like others who had had similar experiences, I was expected to go on living normally. And if others could do it, so could I. In addition to doing everything that was expected of me, I also had to show how tough I was. When I attempted, a few years later, to challenge a few of these discourses, I was served up a big helping of guilt: if you hadn't provoked the events, nothing would have happened. They also led me to understand that I should have anticipated what was going to happen by picking up on the early warning signs. I therefore became convinced that I couldn't trust my intuition. According to Foucault, these discourses were so many technologies of domination meant to keep me docile. In doing so, they marked the construction of my identity and my relationship to my body by mortgaging my power of 
subjectivation. I learned to pretend that nothing had happened and to conceal any impacts from the events. If incest was the origin of the objectification of my body, the discourses that were part of my education definitely strengthened the foundation of this relationship. I am still amazed that I never realized their existence or their impact before becoming involved in a process of somatic education. I was totally unaware of having incorporated them before returning to my sensing body.

\subsection{Objectification of the body and resilience: Going along to get along}

I am 5 years old, and already I am struggling with a body I do not want to have, that I'd like to be able to exchange. To dissociate from it, I try numbing first - because what we can't feel doesn't really hurt. This was to be my way of dealing with a forced cohabitation; for years, I floated between what Levine (1992) calls a dissociative phenomena, and what Hanna (1989) calls sensory motor amnesia, where my sensations were limited and difficult to access. Then after numbing my body, I instrumentalized it; if I wasn't going feel at home in it, at least it should be useful. I presented an illusion, to my family and myself, of having overcome the events of my childhood and returned to normal life; in this way, I was meeting my family's expectations and showing how strong and enduring I was - which echoes Cyrulnik's (1998) definition of resilience. Although problematic, these somatic strategies were so many 'coping mechanisms', as de Becker (2009) calls them, permitting a better representation of myself and enabling me to remain functional, or at least give the impression that I was.

Incest being basically a physical experience, the traumas that result are likely to influence the meaning given to the body. Before I was exposed to somatic education, I had never perceived my 
body as being part of me. Rather, I experienced my body as an object of myself. Chrétien (1996) suggests that when we cut ourself off from our inner world, we objectivize ourself; we cut ourself off from all feelings and become the object of ourself rather than the subject. Such a perception of the body instrumentalizes it, reduces it to the status of a mere tool. Developing my resilience from my deficient relationship to my body, my apparent ability to cope with the events of the past was often detrimental to me. My way of perceiving and treating my body frequently led to physical exhaustion and to several pernicious ways of behaving that were especially destructive because they were asymptomatic. I maintained an eating disorder without ever falling below a certain weight. I consumed large quantities of alcohol and drugs without anyone knowing. I managed to control my episodes so that they went unnoticed. It worked so well that I was myself taken in by the game. In step with the integrated discourses, I succeeded in pretending that everything was fine.

\section{Somatic education: Reconnecting with subjectivity and the felt body}

Once numb, my body was more difficult to feel. Only extreme sensations could bring me back to the experience of my body. I would need to have an entirely new experience to even suspect that something wasn't right, to see that my relationship to my body was problematic. Such a turning point came in the spring of 2007 during an introduction to somatic education. For the first time, I felt my body in some way other than through pain. It was a moment of surprise and intimate connection, etched in my somatic memory forever. This experience awoke a deep desire to gain a better understanding of myself. I realized that feeling good in my body was an alien experience and that my sensing body was unknown to me. With this first awareness, I understood that reconnecting with my feelings was going to require a learning process. 
The Regroupement pour l'éducation somatique (RES) (2014) defines somatic education as the learning of awareness of the living body (the soma) through movement in its environment. The term soma refers to the body experienced from within; according to Joly (2014), it is the sensing body as perceived or 'constructed' by the person. Somatic education is based on a holistic view of the body where the person is considered as a global entity, where the mind and body, as Varela et al. (1974) say, are part of a single system that can organize, adapt and transform itself. Basically, the body is seen as a subject.

The work of the Feldenkrais Method of somatic education is more specifically developed around movement as neurological activity. The method is based on the plasticity of the nervous system and its learning opportunities as well as its functional potential. It also exploits the plasticity of the self and promotes the development of a person's self-image. Awareness Through Movement (ATM) lessons offer structured movement experiences that enable a person to gently become aware of himself or herself. These group lessons are guided by voice while the individual lessons known as Functional Integration (FI) are guided by touch. Although both types of approaches were relevant, I preferred the first, which gave me more independence in my process.

To experience my body as a subject was a turning point. Now, my body is no longer something that belongs to me; I am my body. And I move to the image of who I am. Somatic education quickly generates a reflection that extends beyond movement itself. As the lessons continue, I realize that my way of performing movements reflects my way of being in my daily life. Still, even though somatic education encourages ease and comfort, I tend to push my body and seek its 
limits. I am invited to not do very much and to take breaks, but I persevere and repeat movements that bother or bore me. It is suggested that I go slow to be able to be more present in the experience of the movement, but my mind is elsewhere, making sure that the movement I do is the one that is expected of me. Even though I've heard it repeated many times that the process is more important than the result, I make an effort to do well. And I hasten to imitate what others are doing when I am not able to do what they already seem to grasp. Although slowing down should help me be more aware of my feelings, I surprise myself at times fleeing this new awareness of myself, seeking a new kind of numbness, a place where I will not feel anything. To reproduce what is familiar to me.

What I am learning through somatic education not only helps me to reconnect with my sensations, but also to become aware of my habits, my movements and my behaviour. I am just at the beginning of the process. Becoming aware of one's way of acting and thinking - the two are closely related - is essential for anyone who wants to access and make use of different options. In teaching us to develop our subjectivity and question our perceptions, somatic education feeds a process of self-education through heightened awareness.

\subsection{Self-education: Revisiting what we have learned}

If the individual is constructed according to the constraints that act upon it, it is constantly in the process of a becoming subject. To Foucault, it is possible to acquire knowledge about the rules that have influenced the construction of one's identity. Since identity is the image of ideologies and discourses to which we have been exposed, this includes both new and old, and those that I 
have not chosen as much as those that I can now choose. In this process of actualization, selfimage and subjectivity are adaptive.

Moshe Feldenkrais (1990: 3), founder of the method of somatic education that bears his name, concurs, saying that 'we act in accordance with our self-image'. A movement reflects the state of organization of the nervous system and the image that we construct of ourself and our environment. Among the factors that shape one's self-image are education and self-education. Education makes us an integral member of a family, a community and a society. It tends to integrate individuals into an established structure by determining a language, concepts and behaviours that are common to this particular group. Self-education is in our own hands and is involved in the development of our subjectivity. During childhood, it is coloured by the influence of the family, which is why it becomes difficult to make choices outside of those imposed by the education that comes from our particular environment. Like Foucault, Feldenkrais (1990) believes it is in fact impossible to isolate the construction of identity from its context; the education received has an impact on the individual's self-image and subjectivity. Nevertheless, he says it is up to us to educate ourselves to refine our subjectivity. Self-education provides us the freedom to make choices and therefore a way to learn to help ourselves.

After identifying some of my habits and drawing associations between the way I move and my way of being in the world, my movement exploration gains a new impetus. Exposed to new discourses (those of somatic education), I gradually open myself up to new ways of thinking and acting in the studio. This is a space where I can explore and question my relationship to my body, my relationship with myself. As the lessons progress, the idea of body-as-subject changes 
from being a concept I agree with to a way of experiencing my body to which I give myself access. Because being my body begins to make sense. From a state of numbness, I dive into myself and find a new repertoire of sensations. Lying on the floor, I can feel my tired body, how exhausted I am. Not in pain, just heavy. A state that I learn to accept rather than flee. I give myself permission to do less, to choose not to do some of the suggested motions, just to see how I feel when I take care of myself, when I don't automatically do what others expect of me, when I don't do what other people do. I discover what it means to belong to a group without merging into it, what it means to prioritize my own experience and welcome my feelings rather than to turn them into abstractions. I gradually develop a sense of empowerment over what had been unconsciously incorporated.

Coming to a better understanding of the body relationship I maintain helps me to grow. Through my many Feldenkrais lessons, I come to the realization that the objectification of my body is actually anchored in a number of different types of body relationships. Four of these types have been identified by Tremblay (2011) as critical, functional, efficient and productive body relationships, ${ }^{1}$ which all greatly contribute to my perception of my body-as-object.

As far back as I can remember, I've always hated my body. In addition to holding $\mathrm{it}^{2}$ responsible for the assaults I was subjected to, I thought it was ugly and dirty. It let me down when I participated in sports, unable to recover quickly from injuries. It repeatedly sabotaged my plans. I was just as judgemental about its appearance as its capabilities. As a result of this critical relationship, Tremblay (2011) would say that I put myself down and lacked self-esteem and selfconfidence. I perceived my body’s vulnerability as a weakness. Having learned to overlook and 
criticize my body, I now begin to appreciate it; I gradually come to welcome its uniqueness and focus more on what I like about the image it sends me. I maintain a more positive image of myself since in learning to appreciate my body, I am learning to appreciate who I am.

Over the years, I was regularly put in the presence of my abuser, a situation that I handled by numbing my body. This disconnection enabled me to remain functional within the family unit. I learned to submit my body to authority and pain, to make it the instrument of my daily life. In this functional body relationship, only the utility of my body had a value. If it became tired or if it broke, it slowed me down. After having exploited my body for a long period of time, I am slowly learning to become one with it. If I catch myself at times still feeling hampered by it, I know now to recognize the need to slow down. I am working towards a reharmonization with myself that is not based on preconceived notions of who I am.

Listening to my body had never been an option for me. Overcoming the obstacles of my childhood wasn't easy, it took effort. All my life, I garnered recognition through effort and performance. I tried to control my fears, to outdo what people expected of me. This efficient body relationship was enhanced by my drive to be productive, deriving satisfaction in the number of successes I had accumulated and the quantity of work I had accomplished. Because effort is not valued in the Feldenkrais Method, I am learning to try to conserve my energy and be efficient instead. While this can be challenging in every moment of the life I am living, the idea, once sown, takes root. 
By clarifying and evolving my body relationship, I clarify and evolve my relationship to the world and myself. I relearn to be and to exist.

\subsection{Corporeity and somatic authority: The subject of change}

In order for the meaning of my body to emerge, I must first become aware of myself and access my subjectivity. Corporeity is closely linked to the experience of the self. Chrétien (1996) says that experiencing your body is to be in contact with your current experience and to enter into contact with yourself in order to let the meaning of your identity and your body emerge. The meaning we give our body depends on our relationship with our body. Also, we can assume that the more we are in contact with ourself, the more the meaning of our bodies can emerge. Corporeity is the intersection of physical processes (sensory motor) and the subjective states they support, making the person a body-as-subject in a constant state of becoming, which refers to Foucault (1984) and his conception of a becoming subject that has the power to overcome the constraints acting upon it.

My incorporation of the discourses of my childhood and their impact on my current life were revealed by my practice of Feldenkrais. The method invited me to assign greater importance to my subjectivity by encouraging the development of proprioceptive acuity and reflective thinking. The knowledge gained during this process - about myself and about the constraints that operated on me - raised many questions about my way of being and experiencing my body. I realized that I didn't know how to take care of myself or make choices for myself. To develop somatic authority, I needed to equip myself in order to reclaim this power. Attaining this freedom was not 
without difficulty. I had sought the approval of my parents and my family by subjecting my body to their authority. To free myself would prove to be unsettling at times, even confrontational.

Through the development of somatic authority, I became aware of three new possible body relationships: towards the status quo, between the status quo and change and towards change. ${ }^{3}$ Due to my new awareness, the status quo wasn't really an option. For example, it became inconceivable to maintain the numbness of my body in the presence of my assailant while trying to reconnect with my body through somatic education. In this sense, change was imposed. However, it was a change influenced by my Judaeo-Christian upbringing; I don't accept to be in the presence of my abuser any longer, but neither do I denounce him. At some level of my being, I chose the solution that would make the fewest waves: I excluded myself from family gatherings as a way of taking better care of myself. Between my quest for change and the status quo, I made certain compromises in order to find as much freedom as possible in any given situation. Although my somatic education made the status quo impossible, the change that did come about once again reflected the influence of past discourses. I had at least learned to manoeuvre inside them; this was my way of resisting their power.

The development of somatic authority led to my discovery that to fully free myself, it was not enough to reclaim my body and my sensations, it was also necessary to question the discourses I had incorporated and the education I had received. I had to take responsibility for myself and reshape myself. 


\subsection{Creative self-fashioning and selfing: The plasticity of self}

Philosopher and Feldenkrais practitioner, Richard Shusterman (2000) focuses on the relationship between the soma (lived body) and philosophy, and offers a pragmatic philosophy based on the critical and meliorative study of the body: somaesthetics. According to him, the art of living or experiencing the body and the development of a reflective somatic awareness contribute to creative self-fashioning. Like Feldenkrais, Shusterman (2007) considers that the experience of the body is inseparable from perception, action and thought; and echoing Feldenkrais' notion of self-education, he asserts that somatic learning is the pathway to improving the experience of the body. A learning that is necessary for the evolution of the self.

Beringer (2001) attributes the term 'selfing' to Heinz von Foerster, a contemporary of Feldenkrais. According to her, he discusses the self as a process that evolves though our experiences. Like Foucault, Feldenkrais and Shusterman, he sees the self as neither static nor limited. Selfing is a dynamic model where the self adapts to the totality of our experiences. It is not intended to be a collection of comparative experiences felt by the body, but an integration of meliorative body experiences - like Shusterman's creative self-fashioning. Selfing can also be considered as a self-educational process where, through movement, I learn to recreate the way I move, think, sense and am sensed.

The process I experienced during the three and a half years of autoethnographic study was neither linear nor cumulative. This integrative process was however, rooted in a form of somatic chronology (from unconsciousness to greater self-awareness), both in how I lived and in understanding and incorporating the processes I experienced through the practice of Feldenkrais. 
The more I understood my relationship with myself, the more I could make myself available for the next discovery or open up to new ways of doing things. Without going into details, the following paragraph provides an overview of my experiences in my autoethnographic process.

Becoming aware of my difficulty in feeling my body was the beginning of a sensory quest; I wanted to learn to feel my body, a lot, too much. Through my many initiatives, I came to physically exhaust myself, which I knew resonated with my habit of pushing my body-as-object beyond its limits. In order to not be slowed down by my body, to remain functional and continue my research without revealing anything about my state, I sought an expeditious solution through the use of drugs. I then became aware that I used drugs to numb any kind of unpleasant sensation, the same way I tried to numb my anxiety through the use of alcohol. The inconsistency between my quest to be more in my body and on the other hand, the unconscious numbing of my body, became obvious. So while everyone thought I was in total control of my life (myself included), I came to understand that I engaged in behaviours that mirrored the discourses of my childhood in many ways. I would come to fully reconnect with my felt body by ceasing all use of alcohol and drugs, something I accomplished by integrating sequences of Feldenkrais lessons into my everyday life to manage my anxiety and take care of my felt body.

In this quest for self-education and self-reshaping, movement was the most direct and easiest way to identify what 'I didn't know I didn't know', a notion that Feldenkrais upheld. In fact, it's what enabled me to realize what had escaped me for years: the relationship between the dominant discourses of my childhood and my way of experiencing my body, my way of being in the world. Heightening my awareness through the Feldenkrais Method, I have come to know 
myself better and understand my way of being and acting. To echo Feldenkrais' words, 'from the moment I knew what I was doing, I could do what I wanted'. I would even dare say that from the moment I knew better who I was - with all the discourses involved - I could gradually become who I wanted to be. The idea of the becoming subject could assume its real significance.

\section{Conclusion}

The exploration of awareness can be an effective path for the emancipation of the self. To emancipate ourselves, we must overcome the constraints that act on ourselves. To overcome such constraints, we must regain the freedom to make choices. To make choices, we must be aware of the discourses that affect us.

Becoming aware of the weight of my education was a shock. I knew that incest had had an impact on my way of experiencing my body, but I had no idea that the discourses I had been exposed to were more significant than the events themselves. I thought I was freer than I really was. By enabling myself to reconnect with my body-as-subject, somatic education would develop my subjectivity. For me it was the catalyst for change. And although the old discourses are never far away, the discourse of somatic education opens up a new perception of myself and the world that enables me to resist the status quo. I find inside myself a new maturity.

I believe that what I experienced in my ATM lessons became the basis for the development of my new capacity for insight; learning to know myself and to self-educate was fundamental. Rapidly, my desire to free myself of the constraints that operated on me - and therefore the ones I imposed upon myself unconsciously - led me to challenge the dominant discourse I had 
incorporated. After having learned to objectify my body, I learned to integrate new subjectifying speech; to be my body instead of having a body.

In his teachings, Feldenkrais is not looking for 'flexible bodies, but flexible brains. What [he's] after is to restore each person to their human dignity'. In addition to inspiring my process of subjectivation, somatic education has also enabled me to reconnect with my self-respect.

My article summarizes the potential that somatic education offers for actualization, reharmonization and emancipation of the self. Based on my experience, I believe that the development of somatic consciousness is a subject of investigation that merits further study, especially among victims of sexual aggression. Unknowingly, they too could be maintaining a body relationship determined by discourses they have not chosen.

\section{References}

Beaudry, L. (2011), 'Quitter un ancrage en eaux troubles: l'éducation somatique et le rapport au corps de la femme incestuée (une autoetnographie)'/'Lifting an anchor out of troubled waters: somatic education and its relationship to the female incest victim's body (autoethnography)', M.A. dissertation, Montréal: Université du Québec à Montréal.

Beringer, E. (2001), ‘Self-imaging', The Feldenkrais Journal, 13, pp. 33-38.

Chrétien, M. (1996), 'L'inceste à l'enfance et la relation au corps chez deux femmes adultes: étude comparative de l'expérience du corps chez deux femmes incestuées à l'enfance et deux autres n'ayant pas vécu de traumatisme sexuel'/'Incest in childhood and two women's relationship to the body: a comparative study of the experience of the body in two women who were victims of child abuse and two others who never experienced sexual trauma', M.A. dissertation, Montréal: Université du Québec à Montréal.

Cyrulnik, B. (1998), Ces enfants qui tiennent le coup/'These children who hold out', Paris: Hommes et perspectives. 
de Becker, E. (2009), 'Inceste et facteurs de résilience'/ 'Incest and resilience factors', Annales médico-psychologiques, 167:8, pp. 597-603.

Feldenkrais, M. (1990), Awareness through Movement, San Francisco: HarperCollins.

Fortin, S., Vieira, A. and Tremblay, M. (2008), 'Expérience corporelle des discours de la danse et de l'éducation somatique'/'Bodily experiences of discourses in dance and somatic education', in S. Fortin (ed.), Danse et santé, du corps intime au corps social/Dance and health, from intimate bodies to social bodies, Montréal: PUQ, pp. 115-139.

Foucault, M. (1975), Surveiller et punir: Naissance de la prison/Discipline and Punish: The Birth of the Prison, Paris: Gallimard.

(1984), Histoire de la sexualité, vol. 3: Le souci de soi/The History of Sexuality, Vol. 3: The Care of the Self, Paris, Gallimard.

Hanna, T. (1989), La somatique: comment contrôler par l'esprit la mobilité, la souplesse et la santé du corps/Somatics: Reawakening The Mind's Control Of Movement, Flexibility, And Health, Paris: Inter-Éditions.

Joly, Y. (2014), 'Éducation somatique'/‘Somatic education', http://fr.yvanjoly.com/index.php?title=\%C3\%89ducation_somatique. Accessed 8 June 2014.

Levine, P. (1992), The Body as Healer: Transforming Trauma and Anxiety, Lyons, CO: Author.

Regroupement pour l'éducation somatique (RES) (2014), 'Description', http://www.educationsomatique.ca/edusom/definition/. Accessed 14 June 2014.

Shusterman, R. (2000), 'Somaesthetics and care of the self: The case of Foucault', Monist, 83:4, pp. 532-33.

(2007), Conscience du corps: Pour une soma-esthétique/Body Consciousness: A Philosophy of Mindfulness and Somaesthetics, 2nd edition, Paris: Éditions de l'Éclat.

Tremblay, M. (2011), 'Représentations de la santé et rapports au corps d'étudiants préprofessionnels en danse contemporaine', $\mathrm{Ph} . \mathrm{D}$. dissertation, Montréal: Université du Québec à Montréal.

Varela, F., Maturana, H. and Uribe, R. (1974) 'Autopoiesis: The organization of living systems, its characterization and a model', Biosystems, 5:4, pp. 187-96. 


\section{Contributor details}

Lucie Beaudry holds a master's degree in dance and a postgraduate degree in somatic education (Feldenkrais Method) from the Université du Québec à Montréal (UQAM) as well as a certificate in expressive arts therapy from the Tamalpa Institute in California. She is starting an interdisciplinary doctorate in health and society at UQAM along with a research project that combines somatic education and movement therapy in the context of rehabilitation.

Contact: Université du Québec à Montréal, P.O. Box 63137 - 38 Place du Commerce, Canada, Verdun QC H3E 1 V6.

E-mail: beaudry.lucie@uqam.ca

Notes

${ }^{1}$ The four types of body relationships to which I refer are from a study, conducted by Martyne Tremblay (2011), that centred on the body relationships of sixteen pre-professional dancers and their representation of health. The theoretical framework of the research was based on the sociocultural theory of Pierre Bourdieu who recognizes that the environment leads the individual to incorporate certain norms, values and rules of conduct that can then be found contained in a particular habitus. The author also identified two other types of body relationships in her study: reflexive and hedonistic.

${ }^{2}$ I sometimes use the third person to refer to the body-as-object.

${ }^{3}$ I refer here to the results of an action research conducted by Fortin et al. (2008) with pre-

professional dancers. Based on Foucault's theory, the authors describe how study participants navigated between the dominant discourses associated with contemporary dance and somatic education. The three profiles of body relationships mentioned in my article were identified at the end of this study. 